\title{
Research in partially instrumented experimental watershed in arid lands of Mexico
}

\begin{abstract}
IThe development of sound research is of the highest importance in developing countries within the context of natural resources preservation. The National Institute for Forestry Agricultural and Livestock Research of Mexico has supported an initiative for developing research in experimental - low instrumented watersheds of northern Mexico. In the past few years information on watershed's response to rainfall has been monitored and transferred to users for best management of their rangelands. Alternatives for increasing rainfall productivity have been studied through rain fed and runoff agriculture experiments. Research results coupled with ranchers experience have merged together in a decision support system (expert system) for the better management of natural resources.
\end{abstract}

Volume 2 Issue 3 - 2018

\author{
Ignacio Sanchez Cohen, Miguel A Velasquez \\ Valle, Gerardo Esquivel Arriaga, Palmira B \\ Hurtado, Ramon Gutierrez Luna \\ National Institute of Agricultural Forestry Research and \\ Livestock Nac Center, Mexico
} Correspondence: Ignacio Sanchez Cohen, National Institute
of Agricultural Forestry Research and Livestock Nac Center Mexico, Email sanchez.ignacio@inifap.gob.mx

Received: June 23, 2018 | Published: June 28, 2018

\section{Introduction}

In most developing countries there exist an evident natural resources deterioration due to a variety of causes mainly correlated to risks aversion as lack of sufficient raw materials for many purposes, the need of feeding livestock and the need of growing edible crops for supplemental food. ${ }^{1}$ This situation calls for the need of developing applied research for providing technology related to natural resources management (mainly soil), ${ }^{2}$ The framework for developing research under these situations is the experimental watershed. It is imperative that in watershed research the criteria for the establishment and study of hydrological processes are known suggesting the most appropriate methods and possible ways to guide the research. A common denominator in watershed studies is the lack of essential data and understanding of methods of analysis to interpret and understand the physical phenomena that occur in watersheds. It is also necessary to establish that in watershed studies, the classical statistical methods are not always applicable to hydrological data, and on the other hand, if proper procedures are not followed, the resulting information is of limited application by not developing the appropriate methodology for extrapolation to different watersheds from those where the research has been developed. ${ }^{3}$ The paradigm of research in watersheds must be to express quantitatively the cause and effects relationships between components of the hydrological cycle. Such research should be developed in experimental watersheds (under the influence of man) where "modifiable" variables are controlled by management of natural resources. ${ }^{4}$ proposes a conceptual framework for the design of watershed research.

\section{Some results}

The national Institute for Forestry, Agricultural and Livestock Research of Mexico (INIFAP) has supported the development of research in strategic experimental watersheds of arid northern Mexico. In these watersheds, hydrological information has been obtained for providing basic information to ranchers on the current status of their grassland under the actual management. Trough hydrological monitoring the hydrological behavior of the experimental watersheds has been characterized. The measurement protocol may be utilized in any watershed with scarce instrumentation and may serve for the design of water harvesting or runoff farming systems. Figure 1 shows a gauging device for measuring runoff in the experimental watershed San Luis del Cordero watershed in the state of Durango, Mexico. Within the agricultural portion of the experimental watershed research regarding different options for increasing rainfall productivity in rain feed and runoff agriculture has been developed. Some tillage systems have been evaluated. Figure 2 show some results where direct planting with cero tillage and using $33 \%$ of soil cover with corn residues has been the best option. For widening the impact of the research results, availability of information should be readily available to users and technicians for proper decision taking on natural resources conservation endeavors within watersheds studies. ${ }^{5}$ Also, scientific collaboration between institutions is a crucial aspect for sound research $^{6}$ For instance Sanchez et al., developed an expert system for decision support on rain feed agriculture in Mexico. The system has pre-loaded climatic information from where different scenarios may be analyzed in terms of water availability for crops and to define economical risk (Figure 3).

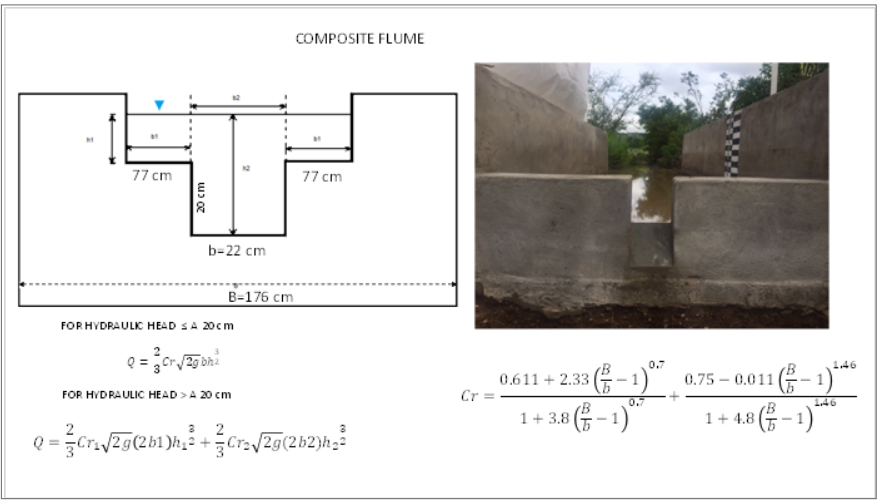

Figure I Composite flume for measuring runoff in an experimental watershed located in the San Luis del Cordero municipality in the state of Durango. 

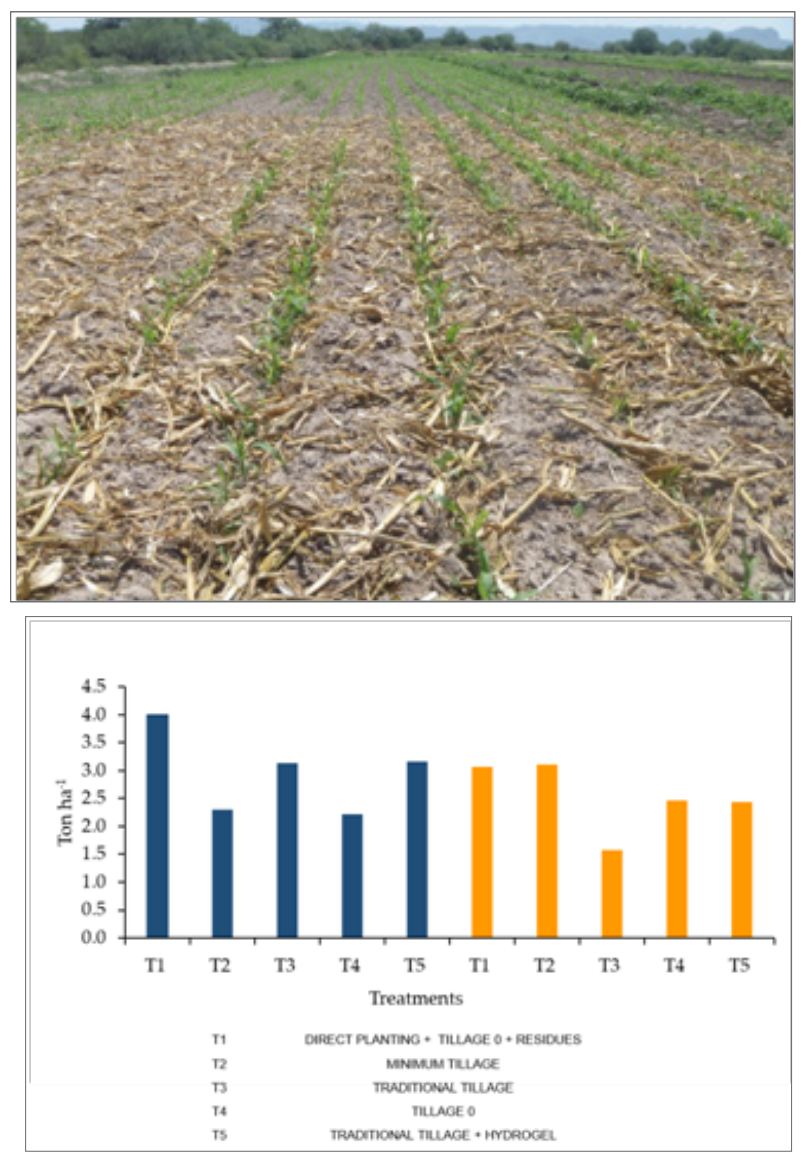

Figure 2 Right: experimental layout for evaluating different conservation agriculture management practices. Left: the best option have been direct seeding with no tillage and leaving in the surface $33 \%$ of corn residues.

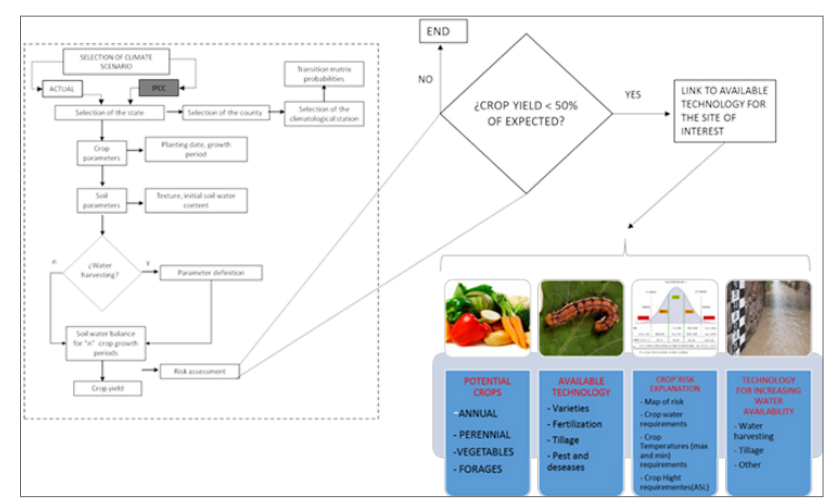

Figure 3 General conceptual diagram of the water balance model and the decision support database. 6

\section{Conclusion}

There is an evident need for scientific development in countries of emergent economies regarding natural resources conservation and planning. The situation has worsened given the impacts of change in climatic patterns. The experimental watershed approach for conducting scientific experimentation and technology generation is the best course of action for preserving natural resources or mitigating deterioration schemes. Transferring of generated knowledge is of crucial importance where decision support systems may play a substantial role.

\section{Acknowledgements}

None.

\section{Conflict of interests}

The author declares there is no conflict of interest.

\section{References}

1. Repetto R, Thomas Holmes. The role of population in resource depletion in developing countries. Population and Development Review. 1983;9(4):609-632.

2. Renard KG, Lane LJ, Simanton JR, et al. Agricultural impacts in an arid environment. Hydrological Science and Technology. 1993;9:145-190.

3. Sanchez-Cohen I, Diaz Padilla G, Velasquez Valle MA, et al. A Decision Support System for Rain feed Agricultural Areas of Mexico. Computers and Electronics in Agriculture. 2015;114(2015):178-188.

4. Sánchez-Cohen I, Díaz PJ, Villanueva D. Integrated Water Management in Mexico: Building a Framework for Research, Paper presented at the Annual Meeting of the Agricultural Research Service. USDA ARS, Tampa Florida. 2007.

5. Heilman PJ, Stones I, Sanchez-Cohen H. Macias Rodriguez and S. R. Mann. Working Smarter: Research and Decision Support Systems in Mexican Agriculture. In: Richardson CW, et al. editors. Modeling and Remote Sensing Applied to Agriculture. USDA ARS INIFAP. 2004;211236.

6. Sánchez Cohen I, González Barrios JL, Díaz Padilla G. Modelo Conceptual en el Manejo Integral del Agua. En: Procesos Hidrológicos en Zonas Áridas y Semi-Áridas. De la Investigación a la Acción. Libro Científico No. 3. INIFAP CENID RASPA. 2007;2-19.

7. Sánchez-Cohen I, Velásquez -Valle MA, Esquivel-Arriaga G. et al Minimum hydrologic characterization for research in experimental watersheds with limited availability of information in arid lands. Revista Chapingo Serie Zonas Áridas. 2015;14(2):185-208. 